\title{
A Study of Newspaper Reading Habits Among Members of the Debaters' Club of Okuapemman School, Akropong-Akuapem.
}

\begin{abstract}
The study sought to find out newspaper reading habits of the Debaters' Club of Okuapemman School, Akropong-Akuapem. Two theories, the Uses and Gratification Theory; and the Dependency Theory underpinned this qualitative study. Purposive sampling and convenient sampling techniques were used to select participants. In all, twelve students were purposively and conveniently selected. Four participants were interviewed and the eight were taken through the focus group discussion. The findings are that the school library is the main source of getting newspapers for the members of the debaters' club. Also, members of the school's debaters' club had varied newspaper reading habits (styles). They scanned or skimmed as well as did an intensive reading. They engaged in silent reading at the school library or engaged in reading aloud when they had the opportunity to read newspapers outside the library or when at home. To them, newspaper reading has been a means of gratification. Since the students who read newspapers could be described as 'scanners,' the paper recommends that teachers should sensitize students on the importance of newspapers in education, and the need to develop good newspaper reading habits as well as overall reading.
\end{abstract}

Keywords: newspaper, reading habits, media, gratification, dependency.

\section{WISDOM MAWULI AWUTTEY ${ }^{1}$}

${ }^{1}$ Wisdom Mawuli Awuttey, M.A, is an English Tutor at the Department of Languages, Okuapemman School, Akropong-Akuapem, Ghana. Email:wmawuttey@gmail.com

\section{Manuscript}

Received 24th April 2020,

Accepted 2nd June 2020,

Published online 9th June 2020.

\section{INTRODUCTION}

Reading is "an art of decoding and constructing messages under and through the word-written message." This definition implies that one can see reading as an attempt by a reader to make sense of a writer's message. "Reading is also regarded as a process, a mode of thinking, a kind of real experience that involves many complex skills; the ability to perceive printed words, to skim for information and then perhaps read intensively." ${ }^{3}$ Here, it is plausible to say that reading is not just about printed matter, but the ability to interpret anything that is intended to convey a message.

"A newspaper is a serial publication containing news, several articles and advertisments." ${ }^{4}$ As a storehouse for information, newspapers provide an avenue for different kinds of people to know their world. ${ }^{5}$ Again, newspapers create reading habits and help to easily differentiate people who read from those who do not read. ${ }^{6}$ The implication is that through newspaper reading a reading culture is created so that one is able to know how people live.

In an argument on the effectiveness of reading English newspapers for improving vocabulary and reading skills of students of Dhaka University, it was stressed that reading English Newspapers helps students acquire much

\footnotetext{
Irshad Hussain and Parveen Munshi, "Identifying Reading Preferences of Secondary School Students," Creative Education 2, no. 5(2007): 431

3 Nor Shahriza A. Karim. \& Amelia Hasan, "Reading Habits and Attitudes in the Digital Age," The Electronic Library 3, no. 25 (2007):285

4 Jehangir Bharucha, “An Analysis of Newspaper Reading Patterns of among the Youth," International Journal of English and Education 6, no.1 (2017):138

Dipika Majumder,“ Newspaper Reading Habits of Private University Students” Journal of Business \& Management 15, (2013):87

6 Ibid.
} 
vocabulary for use, raise reading skills and help improve the speed at which students read. ${ }^{7}$ This is attributed to the rich and vivid content of English newspapers. The writer explained that the language used in newspapers is clearly written and it is one which could be described as a 'day to day language. ${ }^{8}$ It is against this background that the researcher sought to conduct a research to examine newspaper reading habits among members of the debaters' club of Okuapemman School at Akropong-Akuapem.

\section{THE ART OF READING}

Reading Habits: The term 'reading habit' has been defined as "the behaviour which expresses the tastes of reading and the likeness of the individual types of reading." ${ }^{99}$ In other words, it is the pattern with which an individual organizes his or her reading. From another point of view, 'reading habit' is how frequent a student or a learner reads, the manner of reading and the reading preferences of a learner or a student. ${ }^{10}$

The reading habit is individually, socially and culturally constructed in that some external factors such as the environment, education, social background and facilities also influence one's reading habit. ${ }^{11}$ When there are multiple factors, it may yield a particular outcome, that is, habit. Some factors or conditions that may influence the accomplishment of reading habits include accessibility to electronic facilities such as internet at home or at school, availability of home video, school curriculum and the support from teachers. ${ }^{12}$

Generally, reading habits are related to the reader's gender, ${ }^{13}$ age, educational background and advancement of academic performance. It is agreeable that "reading habit is best formed at a young impressionable age in school, but once formed it can last one's life time." "14 has also been argued that "attitudes to reading are set early in the life of an individual, but they are not permanent, whether they are essentially positive or negative." ${ }^{15}$ It is further suggested that reading attitudes of learners seem to be positive in the lower grades than those in the higher grades.

A Malaysian reading profile survey conducted by the National Library of Malaysia in 2010 revealed that Malaysians who were of age ten (10) and above, only read approximately eight to twelve books a year. ${ }^{16}$ It was added that these students reported they also read newspapers, magazines and comics to supplement their reading desire. Here, one would say that girls tend to have a more positive reading attitude than boys for both academic and recreational reading; and that more females read newspapers and magazines than males. ${ }^{17}$ It was also added that sixty-seven percent $(67 \%)$ of girls engage in reading as compared with fifty-four percent $(54 \%)$ of the boys. ${ }^{18}$

A newspaper is an influential medium which helps to spread up-to-date information on local, national and international happenings. ${ }^{19}$ Newspaper reading is a habit which influences an individual or group to discover and enter the storehouse of knowledge on daily basis. "A newspaper reading habit is somewhat established by the time a person reaches twenty-five (25) to thirty years (30) of age." " ${ }^{20}$ This implies that newspaper reading habit must be cultivated in one's early stage of life so the individual becomes 'established' later in life.

Newspaper reading habits could therefore be defined as the rate or the frequency at which students or readers prefer to read newspapers-the daily, the weekly or the bi-weekly subscription that could be accessed.

In determining the newspaper reading habits of students, it is plausible to also identify the kinds of readers that one may encounter. The target audiences of either free or paid newspapers are largely those who are literate. ${ }^{21}$ These audiences may be categorized into three kinds of readers: the habitual readers, the occasional readers and the non-

\footnotetext{
Raju, Ahmmed, "Effectiveness of Reading English Newspapers for Improving Vocabulary and Reading Skills of Students of Dhaka University," The Millennium University Journal 1, no. 1(2016): 68

8 Ibid.

9 Adenyinka Tella and Samson Akande, "Children Reading Habits and Availability of Books in Botswana Primary Schools," The Reading Matrix 7, no.2 (2007): 121

10 Smita Mayekar, "Study on the Impact of Reading Habits on the performance of UG and PG Students," (2010):6

11 Erna Iftanti, "What Makes EFL Students Establish Good Reading Habits," International Journal of Education and Research 3, no. 5 (2015):366

12 Ibid

13 Michael Owusu-Akyeaw and Agatha G. Larson, "Reading Habits among Students and its Effect on Academic Performance," Library Philosophy and Practice (e-journal), (2014): 6-7

14 Ibid., 2

15 Beatrice B. Lukhele, "Exploring relationships between reading attitudes, reading ability and academic performance," Reading and Writing 4, no. 1(2013): 2

16 Ebenzer, K. Pobi, "Reading Habits and its effect on Academic Performance," M.Phil. Thesis UG (2016): 15.

17 Mayekar, "Study on the Impact of Reading Habits,"9

18 Ibid.

19 Ahmmed, "Effectiveness of Reading English Newspapers," 68

20 Majumder,“"Newspaper Reading Habits of Private University Students,” 87

21 Herman Wolswinkel, "Newspaper Reading Behaviour of Young Adults" University of Twenty Master's Thesis (2008): 4
} 
readers. ${ }^{22}$ Habitual readers are those who regularly read and utilize pieces of information received in order to understand their world..$^{23}$ Occasional readers are in search of information but more often spend less time and money on it. ${ }^{24}$ In other words, they are less committed to what they want to read. The non-readers do not think newspapers are interesting enough to spend money or time on. ${ }^{25}$

There are varied reading habits or styles. These include reading aloud, silent reading, hobby reading and recreational reading. It is worth noting that "the single most important activity for building the knowledge required for eventual success is reading." ${ }^{26}$ Reading aloud involves reading to the hearing of the audience. It is often used in the classroom learning situation to develop speaking skills, pronunciation skills and listening skills. In the classroom language learning situation, reading aloud may encompass 'follower reading' where model reading is done by the teacher or by a good student reader and the reading is imitated by the audience. Silent reading on the other hand involves reading a text not to the hearing of the audience but may involve one observing the lips of the reader. It is therefore very valuable for students to spend fifteen (15) to thirty (30) minutes each day reading a book or newspaper or any relevant material of their own choice independently and that the benefits of sustained silent reading cannot be overemphasized. ${ }^{27}$

The habit of reading as a hobby helps one to be versatile in information, ${ }^{28}$ and this enables one to discuss issues knowledgeably with others. According to the International Reading Association, leisure reading is also known as recreational or pleasure reading. ${ }^{29}$ It has been identified as an independent reading, self-selected reading of continuous text for a wide range of personal and social purposes. Recreational or leisure reading can take place in and out of school, at any time. It is generally intrinsically or socially motivated and it is an enjoyable activity for the person who reads. Pleasure reading has also been defined as, "reading that is done in anticipation of the satisfaction it would bring because the reader found the subject matter interesting." ${ }^{30}$ Pleasure reading is therefore an individual experience and so must involve materials that reflect the reader's own choice at a suitable place and time.

Silent reading is further categorized into intensive and extensive reading. Intensive reading and extensive reading are two approaches of reading recognized in Foreign Language Teaching. ${ }^{31}$ Intensive reading "deals with short texts under a teacher's guidance for detailed understanding." ${ }^{32}$ On the other hand, extensive reading involves reading a relatively long text for general understanding. ${ }^{33}$ It is further posited that intensive reading technique involves dividing reading skills into sub-skills and there are detailed skills that could help develop these sub-skills. These skills include recognizing script language, deducing the meaning and the use of familiar lexical items. This technique if effectively used promotes retention of knowledge over a long period of time. Extensive reading rather involves simply reading for pleasure or reading technical, scientific or professional material. To most learners, the form of reading they may be conversant with is skimming and scanning. While scanning is done in order to get key details, skimming is most useful for essential information. The success of intensive reading stems from the premise that the more familiar the reader is with diverse reading materials, the more comprehension is promoted. ${ }^{34}$

Referencing the 'Ruotolo's Methodology' where fifty-six (56) newspaper readers in Brazil are purposively selected, five types of newspaper readers are identified..$^{35}$ There are the instrumental readers who use newspapers to get the information which serves as instrument for their day to day life. Instrumental readers embrace information from their community and the world in order to analyze and understand daily happenings around them. Another type of newspaper readers are the opinion makers. These readers primarily use information to form and confirm the opinion of other newsmakers and editors. In order for the opinion makers to understand new events, they compare opinions. There are also pleasure readers who utilize newspapers for entertainment purposes. Reading newspapers becomes part of their daily routines and they love 'the fun' or the enjoyment associated with it. The fourth type of readers uses newspapers as ego boosters. These people read newspapers to enhance self-image and status. Ego boosters use newspapers to facilitate their social contact as well as creating sensational companionship. The fifth type of readers is "scanners - readers with

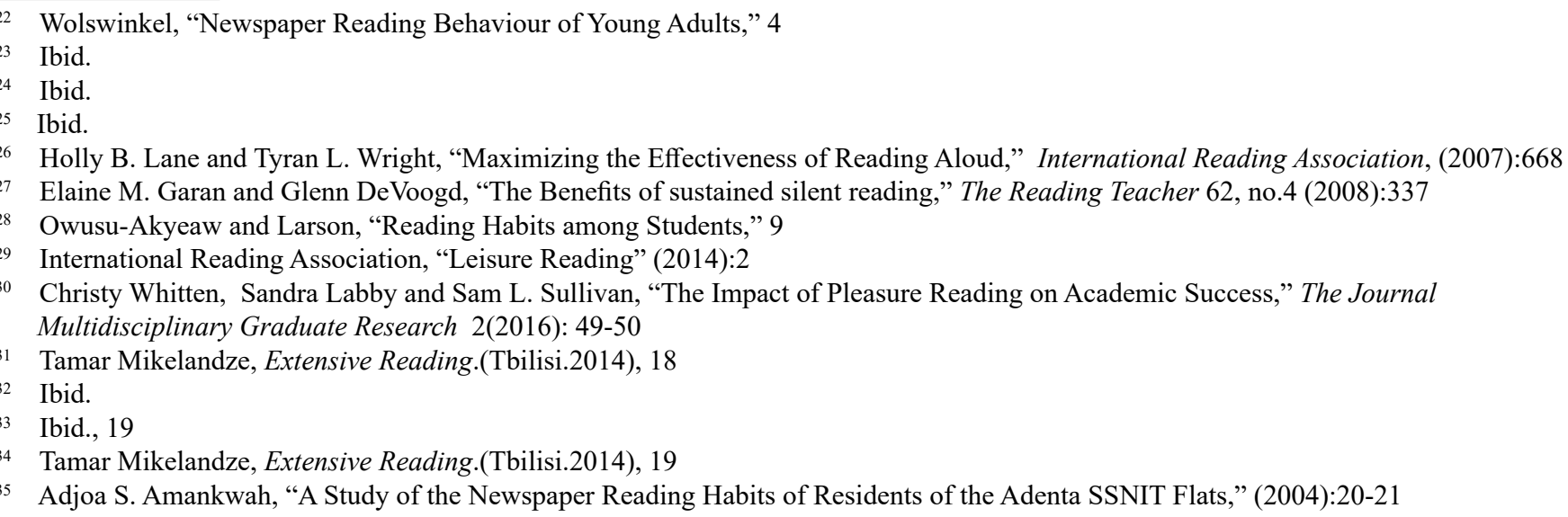


a variety of motives such as information, guidance, validation of opinions and participation," ${ }^{36}$ and these qualities are contained in the other four categories.

The implication from this assertion is that the motives for reading newspapers provide reasoning which falls in line with the Uses and Gratification Theory of Mass Communication.

Developing a habit for Newspaper reading: The habit of newspaper reading depends on several factors. ${ }^{37}$ These factors include reading at least three or more times per week, preferably daily, reading more than fifteen (15) minutes a day, having a stable method of getting the paper, and having a particular time and place to read the paper. These will promote a defined pattern of reading. It is agreeable here to state that "the content of newspapers is generally presented in style and language, which are much above the reading and comprehension levels of the average literate Ghanaian," 38 in that some students of Okuapemman School will have to do a 'rereading' or conduct a 'purposeful' reading of Ghanaian newspapers in order to go beyond the 'surface meaning'.

Touching on why students read, is the ability to develop one's mind. ${ }^{39}$ Reading therefore could be a basic ingredient for developing the mind or the intellect of individuals. Additionally, when one cultivates the habit of reading, it influences the promotion of one's personal development in particular and social progress in general. ${ }^{40}$ Also, reading makes way for a better understanding of one's own experiences and it can be an exciting voyage to self-discovery. ${ }^{41}$ Reading does not come naturally to a human being. It must be acquired and cultivated. Here, one would say that a reader does not only learn what has been discovered by others but also build on the foundation of information. Students therefore tend to know who they really are in terms of what they can read and how well they can do it.

When learners engage in the practice of newspaper reading, they tend to experience improvement in their attitudes towards overall reading. ${ }^{42}$ It also helps convey the feeling that one belongs to the "reading club" and this is a demonstration of social acceptance. Most adolescents in senior high schools would crave for 'the sense of belonging' and so resort to newspaper reading.

Newspaper reading by young adults or high school students is related largely to their attitude towards news in general. ${ }^{43}$ Young people perceive news as very important but this belief does not lead to watching news themselves. ${ }^{44}$ In the opinion of young people, news is basic social service which has to be available when one needs it. ${ }^{45}$ This means that among young people, there seem no automatic correlation between actually watching television news programme and the significance attributed to the same news programme. The presupposition here is that newspaper reading among young people falls into this paradox and that where newspapers may be available, young people may not read them.

Reading newspapers helps audience-users to "know the outer world" alongside the other advantages of encouraging readers' participation in class. ${ }^{46}$ Students who engage in habitual newspaper reading are well-informed of things that happen both within and outside the classroom environment. When this happens, learners in a competitive environment tend to gain greater advantage over their counterparts in terms of academic progression.

One of the factors that affect students' newspaper reading is the poor school environment. ${ }^{47}$ This stems from hostile librarians, unsupportive teachers and inadequate reading materials. For instance, the instructional approaches and materials used in the school environment by the teacher may pose challenges to newspaper reading. ${ }^{48}$ Another challenge to newspaper reading is access and habit of the individual reader. It is agreeable that "when young people have regular access to newspaper at home" they tend to read newspaper. ${ }^{49} \mathrm{Here}$, a 'home-habit' might have been formed and could be transferred into the school environment. The assumption here is that a student who most often reads newspaper at school might have had regular access to it at home.

From another viewpoint, insufficient copies of newspapers at the school library, newspapers not always provided on time and limited space at the school's library, ${ }^{50}$ were among barriers to newspapers reading by postgraduate students. Senior high school students in Ghana especially those at Okuapemman School face similar

36 Amankwah, "A Study of the Newspaper Reading Habits," 22

37 Dipika Majumder, “Newspaper Reading Habits of Private University Students” Journal of Business \& Management 15, (2013): 90

38 Modestus Fosu, “A Linguistic Description of Ghanaian Newspapers," Ghana Journal of Linguistic 5, no. 1(2016):4

39 Mayekar, "A Study of the Impact of Reading Habits on Academic Performance," 3

40 Ibid.

41 Owusu-Akyeaw and Larson, "Reading Habits among Students," 2

42 Ahmmed, "Effectiveness of Reading English Newspapers," 68

43 Wolswinkel, "Newspaper Reading Behaviour of Young Adults," 6

44 Ibid.

45 Ibid.

46 Kumar, "Newspaper Reading Habits," 174

47 Tella and Akande , "Children Reading Habits and Availability of Books," 121

48 Wolswinkel, "Newspaper Reading Behaviour of Young Adults," 8

49 Ibid.

50 Kumar, "Newspaper Reading Habits," 187-188 
challenges. One would also argue that students with poor language skills fail to appreciate the complex language skills of the writers of newspapers. In terms of readability of Ghanaian newspapers, it has been observed that, "The content of newspapers is generally presented in style and language, which are much above the reading and comprehension levels of the average literate Ghanaian, junior high school-educated reader." ${ }^{11}$ The Ghanaian newspaper uses "Big English." ${ }^{52}$ This suggests that through the use of the "Big English" which has been defined as 'bulky,' 'unwieldy,' 'officous'and 'authoritative,' most first and second year Debaters' Club members might not get the right meaning from newspaper messages and this too is a challenge for others students of Okuapemman School.

Uses and Gratifications Theory: The theory of Uses and Gratifications is one of the theories that provide an appropriate framework for this study. Gratification simply refers to the satisfaction or reward the audience expects or receives from media use. This theory is largely attributed to the research of Elihu Katz, Jay Blumler and Michael Gurenvitch in 1974. ${ }^{53}$ Its main focus is on how people use the media. The theory postulates that media users consist of active rather than passive individuals who demand something from the media to which they are exposed. ${ }^{54}$ The choice media users make is dependent on what gratifications they perceive the media provides. This is to say that people depend on media to meet their specific needs. Therefore, "the gratifications the individual seeks from the media are determined by his or her attitude towards the media" ${ }^{55}$ and that the increased dependence on media, in turn, increases media influence on people's lives. Media has therefore been considered as one of the contributing factors to meeting the needs of people. This implies that newspaper users tend to patronize particular newspapers based on what satisfaction they get from them.

Also, the level of perceived satisfaction depends on the needs or interests of the individual. ${ }^{56}$ The more an individual perceives the content of a media more satisfying, the greater the chance to choose it. For instance, if respondent-newspaper users at Okuapemman School perceive that the information they need would be found in a particular newspaper, they would select that and read to meet their needs. For example, a Foods and Nutrition student may come across a recipe column in the Mirror and may draw the attention of her colleagues to read it because of the satisfaction (new knowledge) they would gain from the 'recipe column.'

Dependency Theory: Another theory that explains this study is the Dependency Theory of audience-media society and it helps explain the effects of media on audience users. Dependency Theory emphasises the existence of interactions between social institutions, media systems and audiences that generate needs, interests and motives. ${ }^{57}$ This relationship that exists between the societal establishments and the media systems tend to have an influence on the selection of several media and non-media sources. ${ }^{58}$ This results in audience dependence on media information to meet certain needs and to achieve certain goals. However, an audience-user does not depend on all media equally. ${ }^{59}$ Here, two factors determine how dependent the audience-member becomes on any given medium. ${ }^{60}$ First, dependency on media is based on the fact that it satisfies a number of needs and not just a few. Among the numerous functions of media such as reporting news, providing entertainment and monitoring political activities, an individual or a group of people becomes dependent on the medium that meets more than one need. ${ }^{61}$ For instance, a member of the Debater's Club of Okuapemman School preparing for a regional contest is likely to read news items and articles in the Daily Graphic, the Ghanaian Times and even try getting access to online information.

Secondly, media dependency is based on social stability. ${ }^{62}$ When conflicts arise or when there is social change, established institutions, beliefs and practices are challenged and hence this may force a review and probably a new choice in media consumption. ${ }^{63}$ During such 'revolutionary periods,' there is much reliance on media. ${ }^{64}$ On the other hand, at stable periods, dependence on the media may go down. For instance, the Daily Graphic was one of the popular print media outlets that carried the news of how some students of the Kwame Nkrumah University of Science and Technology (KNUST), Kumasi-Ghana had engaged in a violent demonstration against the university management

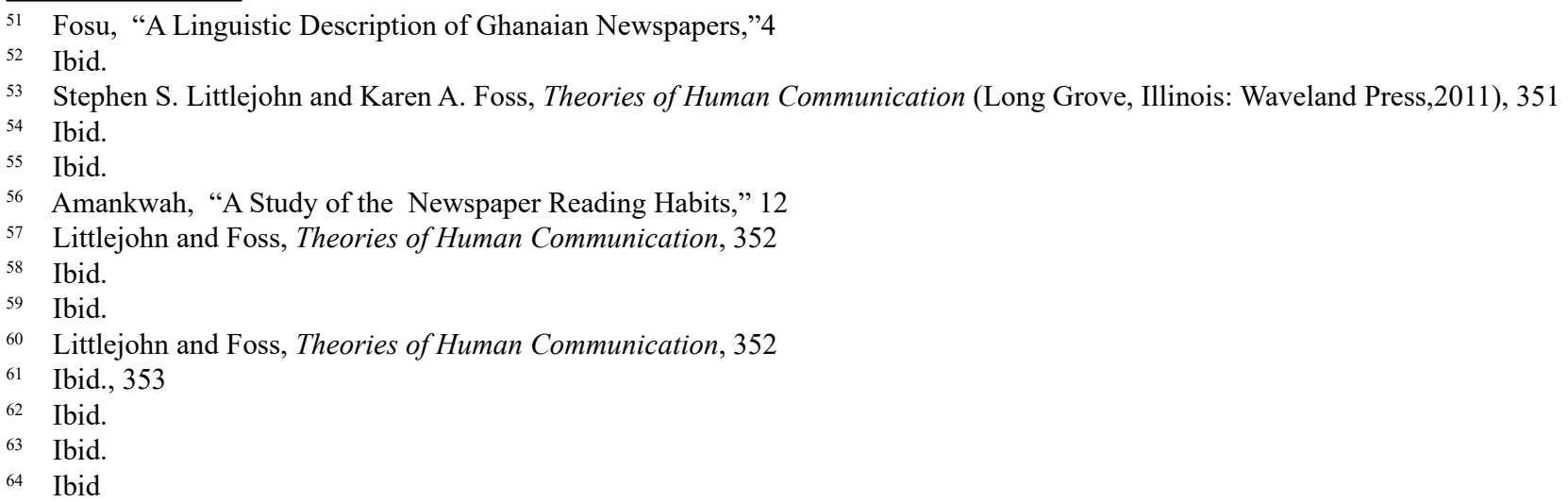


which caused the Ashanti Regional Security Council (REGSEC) to close down the university for some days ${ }^{65}$ and subsequently, the Government of Ghana had to dissolve the Governing Council of the university ${ }^{66}$

During the three-week KNUST impasse, it was observed that the most active readers of newspapers at Okuapemman School were students who had relatives or friends at KNUST. These readers relied on the Daily Graphic and the Ghanaian Times for much information. However, when the KNUST brouhaha was over, four weeks after the KNUST students had reported back to school, the general OKUAS student populace seemed to have forgotten about KNUST.

\section{METHODOLOGY}

The research approach for the study was the qualitative method. The researcher sought to understand and interpret more local meanings, that is, making efforts to arrive at knowledge that contributes to general meaning and this approach allowed for a far richer understanding of a trend suitable in terms of questioning, where participants framed responses in their own terms of reference, rather than having them pre-framed by the researcher. ${ }^{67}$

In this study, the behaviour involved the newspaper reading habits of the Debaters' Club of Okuapemman School: habits or behaviours of students displayed over a period of time. The researcher used participant observations in order to identify what materials students read at the library. Observational data has been useful to uncover the reading behaviour of which the participants themselves might not have been aware of ${ }^{68}$ Also, semi-structured questions were used in identifying the reading preferences of these students. This helped the researcher to identify newspaper users from non-users and also led to the purposive selection of participants. Purposive sampling and convenient sampling techniques were used in selecting participants for the study. This method is used when the researcher selects individuals and sites for study because they have knowledge and willingly give an understanding of the research problem or the fundamental phenomenon in the study. ${ }^{69}$ Interviews have been considered as the most common method of data collection in qualitative research. ${ }^{70}$ The researcher wanted participants to have the opportunity to discuss the subject of newspaper reading in their own words as much as possible. Another significant reason for the choice of interviews as a tool for this study was that interviews could be used to answer factor-type questions ${ }^{71}$ such as the factors influencing the newspaper reading of senior high school students. An interview guide was designed by the researcher to guide the "conversation" 72 based on the literature review and the knowledge acquired during a similar interview with students.

The focus group discussion and the interviews were conducted in the months of October and November 2018. The researcher semi-structured interviews and used focus group discussion as data collection instruments in order to get meaningful data to complete the study. Focus group discussions have been potentially useful as the researcher sought a kind of social change. ${ }^{73}$ Participants' involvement in group interaction would become a tool for social change. ${ }^{74}$ The researcher desired that participants' group interaction behaviour would improve since they would learn better group communication dynamics such as tolerance, good listening skills and critical thinking skills in their subsequent encounters.

Through the purposive and convenient sampling techniques, a total of twelve (12) participants were selected from sixty (60) active members of the Debaters' Club of Okuapemman School. Eight (8) were females and four (4) males. Out of this number, two of the male participants were the school's library prefects and one of them was the principal speaker for the debating team. Since the library prefects helped in organizing the library for use by both teachers and students; they had greater opportunity of reading newspapers and therefore provided more useful responses. The females outnumbered the males in the sense that the females at Okuapemman School were always available for questioning. The participants were all final year students of Okuapemman School.

\footnotetext{
65 Kwame Baffoe Donkor, “KNUST Closed Down,” Daily Graphic, October 23, 2018

66 Enoch Darfah Frimpong, "KNUST Governing Council Dissolved," Daily Graphic, October 25, 2018 edition.

${ }_{67}$ John W.Creswell, Qualitative Research Inquiry and Research Design: choosing among five approaches (Los Angeles: SAGE Publications, 2013), 47-48

${ }_{68}$ Nouria Bricki and Judith Green, “A Guide to Using Qualitative Research Methodology,” MSF Research (2018):20

69 Ilker Etikan,Sulaiman Abubakar Musa and Rukayya Sunusi Alkassim. "Comparison of Convenience Sampling and Purposive Sampling," American Journal of Theoretical Applied Statistics 5, no. 1(2016):2

70 Virginia Braun and Victoria Clarke, Successful Qualitative Research: A practical guide for Beginners, ( London: SAGE Publications,2014), 77-79

71 Braun and Clarke, Successful Qualitative Research:81

72 Ibid.

73 Braun and Clarke, Successful Qualitative Research :110-111

74 Ibid.
} 


\section{FINDINGS}

Table 1: Time spent by students on newspaper reading

\begin{tabular}{|l|l|l|}
\hline Time spent & Number of Participants & Percentage \\
\hline Less than 30minutes & 0 & nil \\
\hline 30-60 minutes & 11 & 91.67 \\
\hline More than 60minutes & 1 & 8.33 \\
\hline Total & $\mathbf{1 2}$ & $\mathbf{1 0 0}$ \\
\hline
\end{tabular}

All four (4) participants affirmed that the library was the only source of getting newspapers to read except for a female participant. The four (4) participants in the interview were questioned on the maximum time spent in a week for newspaper reading. Out of the four, three (3) made it known that they spent thirty (30) to sixty (60) minutes for reading newspapers. This was usually during the one-hour library schedule on the timetable. The other participant, however, acknowledged that she spends more than one hour on reading newspapers. This was not done at the school's library but in her dormitory or in any convenient place in the school. When asked how feasible her situation was especially at Okuapemman School, it was revealed that she was always provided with newspapers by her parents any time they paid her a visit. Here, it is justifiable that the participant's behaviour of spending extra minutes outside the library section stems from her perceived satisfaction derived from newspaper use. Consequently, her long hours of newspaper become a habit. She could not hold but respond, "The more time I spend reading newspaper, the more I know and convinced I would get more vocabulary for everyday use." 75 In effect, her high level of newspaper satisfaction affects her beliefs and this leads to reinforcement of this habit. ${ }^{76}$

From the focus group discussion, it was revealed that all eight (8) participants resorted to the library as their only source of newspaper reading. They spend a maximum of fifty (50) minutes on reading newspapers each week. In this dimension, the eight (8) participants could be described as having low level of newspaper satisfaction. In that they are not compelled to go the extra mile for another source of newspaper.

Table 2: Style of reading newspaper

\begin{tabular}{|l|l|l|}
\hline Style of reading & Number of Participants & Degree \\
\hline Skimming / scanning & 4 & 180 \\
\hline Close reading & 2 & 90 \\
\hline Both & 2 & 90 \\
\hline Totals & $\mathbf{8}$ & $\mathbf{3 6 0}$ \\
\hline
\end{tabular}

During the period of study, the researcher observed that learners who read newspapers at the school library engaged in silent reading. However, during the interview with the key participants of the debaters' club, it was revealed that a student could not engage in reading aloud at the library. That behaviour if detected is reciprocated with threats of punishment from the supervisor or the librarian. The desire to read aloud has been attributed to the fact that reading newspaper for specific information may require that the learner memorizes fact, or the facts required. For instance, a principal speaker in an interschool debate may have to get useful facts that could be presented as exhibits and such information is better appreciated if memorized. It was also revealed that most participants skimmed or scanned through newspapers. Two (2) of the participants, disclosed that they did what they termed "close reading." It was also made known from participants that other students who patronized the school library were also 'occasional' readers of newspaper. The occasional readers use newspaper to satisfy just a few needs. The more they find newspaper as providing adequate information, entertainment and keep them busy during library section, they become dependent on this source. ${ }^{77}$

Table 3: Opinions of students on why they read newspapers

\begin{tabular}{|l|l|l|}
\hline Reasons for reading & Number of Participants & Percentage \\
\hline For information & 3 & 2.5 \\
\hline Vocabulary acquisition & 2 & 16.67 \\
\hline Hobby & 4 & 33.33 \\
\hline
\end{tabular}

\footnotetext{
Oyortey Hadassah Korkor. Interview. October 14, 2018

76 Littlejohn and Foss, Theories of Human Communication, 351

77 Littlejohn and Foss, Theories of Human Communication, 353
} 


\begin{tabular}{|l|l|l|}
\hline Entertainment / fun & 2 & 16.67 \\
\hline To kill time & 1 & 8.33 \\
\hline Total & $\mathbf{1 2}$ & $\mathbf{1 0 0}$ \\
\hline
\end{tabular}

From the focus group discussion, it was revealed that all the eight (8) participants (representing 100 percent) read newspapers in order to get the latest information that the media reports. While in school, they are not privy to important news or occurrences outside the school environment. Participants make use of the one-hour allocation for library on the school time table to engage in newspaper reading so that they could get satisfaction from its use. ${ }^{78}$ Out of the four key participants who were engaged, three (3) confirmed that they read newspapers because it complemented information that teachers and good textbooks provide. A participant disclosed that the Daily Graphic for instance, has columns purposely dedicated to articles. "Articles are indispensable to every student of English,",79 she added.

\section{DISCUSSION}

This study examined newspaper reading habits of the debaters' club of Okuapemman School. Although many educators and stakeholders in education believe that senior high schools are supplied with newspapers, just a few of these stakeholders have considered how effective the newspapers have been utilized by students. The evidence from the methodology employed showed that Okuapemman School has a schedule on the school timetable which gives students the opportunity to read newspapers. Though it is evident that there is the challenge of availability and easy access to newspaper at Okuapemman School, participants have adopted their strategy of sharing the double-page copies of newspaper available among themselves. "This has been achievable because we sometimes plan what we want to do at the library." ${ }^{80}$ In one view, addressing the problem of availability and accessibility of newspapers in senior high schools would help infuse a sense of social responsibility as well as providing students with news and analyses of issues that promote societal advancement. ${ }^{81}$

It was evident that the most members of the Okuapemman School Debaters' Club who read newspapers could be described as 'scanners' ${ }^{82}$ They read newspapers with a variety of motives such as for the purpose of information, for opinion validation and participation. At Okuapemman School library, the Daily Graphic, Mirror, and Spectator provide some form of entertainment to users. There are columns that provide 'fun' such as celebrity news, puzzles, and fashionable dress styles. One female participant said she is always happy when she sees fashionable dresses displayed in the media. This gives her emotional satisfaction. "There is a kind of good feeling I get when I see those lovely and trendy pictures, ${ }^{, 83}$ she added. It is agreeable to say that the newspaper user in this domain has found more than one form of gratification and that led to dependence on it. The situation agrees with Ball-Rokeach and De-Fleur's assertion that the individual may become dependent more on a media that meets a number of needs ${ }^{84}$

Taking a look at newspaper reading habits of these students, those who adopt intensive reading of newspaper are those who are mainly involved in formal arguments such as debates. This is due to the need to gather much information from several sources. Students who most often read newspapers at the library usually engage in silent reading. They either do intensive or extensive reading. One male participant said that much is acquired during such a time and this complements knowledge gained from teachers and textbooks. ${ }^{85}$

Teachers should therefore sensitize students on the importance of newspapers in education and the need to develop good newspaper reading habits as well as overall reading. It has therefore been suggested that the school library committee designates a newspaper section at the library to help promote a better newspaper reading culture at Okuapemman School. School management should procure at least three copies of the Mirror and any other senior-high friendly newspaper for student use at the library in order to motivate learners in newspaper reading. When this becomes more fruitful, an award scheme should be instituted to promote newspaper reading competitions.

\section{CONCLUSION}

This study has provided an overview of newspaper reading habits among members of the Debaters' Club of Okuapemman

\footnotetext{
Littlejohn and Foss, Theories of Human Communication, 351

Oyortey Hadassah Korkor. Interview. October 14, 2018

80 Ama Offei-Larbi. Focus Group Discussion. November 2, 2018

81 Eamin Ali A. K. Akanda and Armanul Haque, "Newspaper Reading Habits of University Graduate Students in Bangladesh: A case study," IMPACT-International Journal of Research in Applied Natural and Social Sciences 1, no. 3 (2013):3

82 Amankwah, "A Study of Newspaper Reading Habits," 22

83 Ama Offei-Larbi. Focus Group Discussion. November 2, 2018

84 Littlejohn and Foss, Theories of Human Communication, 353

85 Sackey, Samuel. Interview. October 19, 2018
} 
School. It also has a brief review of literature. Here, two theories, the Uses and Gratification Theory; and the Dependency Theory underpinned this qualitative study. The findings showed participants' reasons for newspaper reading and the gratification they sought. This study is significant to stakeholders in the Ghana Education Service and then would serve as a theoretical framework for increasing newspaper readership in senior high schools in Ghana.

\section{BIBLIOGRAPHY}

Ahmmed, Raju. "Effectiveness of Reading English Newspapers for Improving Vocabulary and Reading Skills of Students of Dhaka University," The Millennium University Journal 1,no.1(2016): 68-76.

Akanda, Eamin Ali A.K. and Haque, Armanul. "Newspaper Reading Habits of University Graduate Students in Bangladesh: A case study." IMPACT-International Journal of Research in Applied Natural and Social Sciences 1, no. 3 (2013):1-8

Amankwah, Adjoa S. "A Study of the Newspaper Reading Habits of Residents of the Adenta SSNIT Flats," (2004): M. Phil Thesis UG. https://www.ssrn.com/abstract $=1655740$

Braun, Virginia and Clarke, Clarke. Successful Qualitative Research: A practical guide for Beginners. (London: SAGE Publications, 2014)

Bharucha, Jehangir. “An Analysis of Newspaper Reading Patterns of among the Youth."International Journal of English and Education 6, no.1 (2017):138-146

Bricki, Nouria and Green, Judith. "A Guide to Using Qualitative Research Methodology,” MSF Research (2018):1-20. http://hdl.handle.net/10144/84230

Creswell, John W. Qualitative Research Inquiry and Research Design: choosing among five approaches (Los Angeles: SAGE Publications, 2013).

Donkor, Kwame Baffoe. "KNUST Closed Down.” Daily Graphic, October 23, 2018 edition.

Etikan Ilker, Musa Sulaiman Abubakar and Alkassim Rukayya Sunusi. "Comparison of Convenience Sampling and Purposive Sampling," American Journal of Theoretical Applied Statistics 5, no. 1(2016):1-4. doi:10.11648/j.atas.20160501.11

Fosu, Modestus. "A Linguistic Description of Ghanaian Newspapers: implications for the readability, comprehensibility and information function of the Ghanaian Press." Ghana Journal of Linguistic 5, no. 1(2016):1-36. https://www.researchgate.net/publication/318135217

Frimpong, Darfah Enoch. "KNUST Governing Council Dissolved," Daily Graphic, October 25, 2018 edition

Garan, Elaine M. and DeVoogd, Glenn. "The Benefits of Sustained Silent Reading: Scientific Research and Common Sense Converge." The Reading Teacher 62, no.4 (2008):336-344. Doi: 10.1598/RT.62.4.6

Hussain, Irshad. \& Munshi, Parveen, "Identifying Reading Preferences of Secondary School Students."Creative Education 2, no.5 (2007):429-434. Doi:10.4236/ce.2011.25062

Iftanti, Erna. "What Makes EFL Students Establish Good Reading Habits." International Journal of Education and Research 3, no.5 (2015): 365-374. https://www.ijern.com/journal/2015/May-2015/31.pdf

Karim, Nor Shahriza A. \& Hasan, Amelia "Reading Habits and Attitudes in the Digital Age," The Electronic Library 3, no. 25 (2007):285-298

Kumar, A., Nagarajan, M. \& Prabhakar, S. “Newspaper Reading Habits: A Case Study.” International Journal of Information Movement 2, no.6 (2017), 174-188. http://www.ijim.in/wp-content/uploads/2017/10/Vol-2-Issue-VI-174-188-paper-25-5-A-kumarNEWSPAPER-READING-HABITS-A-CASE-STUDY.pdf

Lane, Holly B. and Wright, Tyran L. "Maximizing the Effectiveness of Reading Aloud." International Reading Association, (2007):668-675. Doi:10.1598/RT.60.7.7

"Leisure Reading." International Reading Association (2014). http://literacyworldwide.org/docs/default-source/where-we-stand/leisure-reading-position-statement.pdf

Littlejohn, Stephen S. and Foss, Karen A. Theories of Human Communication. (Long Grove, Illinois: Waveland Press, 2011)

Lukhele, Beatrice B. "Exploring relationships between reading attitudes, reading ability and academic performance amongst primary teacher trainees in Swaziland." Reading and Writing 4, no.1 (2013). DOI:10.4102/rw.v4i1.28

Majumder, Dipika, "Newspaper Reading Habits of Private University Students: A Case Study on World University of Bangladesh. ” OSR Journal of Business and Management 12, no.1 (2013), 87-91. 
http://www.iosrjournals.org/iosr-jbm/papers/Vol12-issue1/L01218791.pdf?id=3538

Mayekar, Smita. "Study on the Impact of Reading Habits on the performance of UG and PG

Students," (2010): Solapur: Hirachnand Nemchand College of Commerce.

http://hnccsolapur.org/wp-content/uploads/2010/07/MRP-Mayekar.pdf

Mikelandze, Tamar. Extensive Reading. (Tbilisi.2014). https://www.academia.edu/14846898

Owusu-Akyeaw Michael, and Larson, Agatha A. "Reading Habits among Students and its Effect on Academic Performance: a Study of Students of Koforidua Polytechnic," Library Philosophy and Practice (2014). http://digitalcommons.unl.edu/libphilprac/1130.

Pobi, Ebenezer K. "Reading Habits and its effect on Academic Performance," M.Phil Thesis UG (2016): 189 http://ugspace.ug.edu.gh/bitstream/handle/123456789/23378/Reading\%20Habits\%20And\%20 Its $\% 20$ Effect $\% 20$ On $\% 20$ Academic $\% 20$ Performance $\% 20$ Of $\% 20$ The $\% 20$ Students $\% 20$ Of $\% 20$ St. $\% 20$ John\%E2\%80\%99s\%20Grammar\%20Senior\%20High\%20Secondary\%20Schoo1\%2C\%20Accra. pdf? sequence $=1 \&$ isAllowed $=\mathrm{y}$

Tella, Adenyinka and Akande, Samson. "Children Reading Habits and Availability of Books in Botswana Primary Schools," The Reading Matrix 7, no.2 (2007): 117-142

Whitten, Christy., Labby Sandra and Sullivan, Sam L."The Impact of Pleasure Reading on Academic Success." The Journal Multidisciplinary Graduate Research 2(2016): 49-50

Wolswinkel, Herman."Newspaper Reading Behaviour of Young Adults" (2008). https://pdfs.semanticscholar.org/e0f1/d9f3b1e2782b653012362ddb6bbfca5e2eda.pdf? $\mathrm{ga}=2.257811086 .440082619 .1588890289-1002251406.1588890289$ 